\title{
Genetic heterogeneity of Usher syndrome type II in a Dutch population
}

\author{
S Pieke-Dahl, A van Aarem, A Dobin, C W R J Cremers, W J Kimberling
}

\begin{abstract}
The Usher syndromes are a group of autosomal recessive disorders characterised by retinitis pigmentosa (RP) with congenital, stable (non-progressive) sensorineural hearing loss. Profound deafness, RP, and no vestibular responses are features of Usher type I, whereas moderate to severe hearing loss and $R P$ with normal vestibular function describe Usher type II. The gene responsible for most cases of Usher II, USH2a, is on chromosome 1q41; at least one other Usher II gene (as yet unlinked) is known to exist. Usher III presents with a progressive hearing loss that can mimic the audiometric profile seen in Usher II. A gene causing Usher III in a group of Finnish families, USH3, resides on chromosome 3q. Since the phenotypes for Usher II and III overlap, it is important to determine how frequently Usher IIa, Usher IIb, and Usher III occur in a clinical population of non-Usher I patients. DNA was collected from 29 Dutch families and genotyped with six DNA markers known to flank the USH2a gene closely, and with five markers that flank USH3. Results of haplotype and linkage analysis were consistent with linkage to the USH2a locus in 26 of these 29 Dutch families. Three families displayed no linkage to 1q41 markers, and one of these three families appeared unlinked to 3q markers as well; current haplotypes of the other two families are inconclusive for linkage with the USH3 locus without further genotyping. While an $A$ test for heterogeneity of USH2a was statistically significant, no convincing evidence of linkage to USH3 was found in this Dutch sample. Consequently, the frequency of the unlinked variety of Usher IIa (Usher IIb) in The Netherlands was estimated as 0.104 . To determine if marker alleles could be used to differentiate Usher type IIa from Usher IIb, parental chromosomes of the 26 Usher IIa families were analysed for significant non-random association of specific alleles from flanking loci with USH2a, but no linkage disequilibrium was observed in this Dutch population. (f Med Genet 1996;33:753-757)
\end{abstract}

Key words: genetic heterogeneity; Usher syndrome type II; Dutch population.

Usher syndrome (US) is defined as hearing loss or deafness with retinitis pigmentosa (RP).
In 1959, Hallgren ${ }^{1}$ laid the foundation for the clinical definition of US in a study of 172 US patients from Sweden. Hallgren ${ }^{1}$ showed significant phenotypic heterogeneity of US by describing two clinically distinct forms, Usher syndrome type I and Usher syndrome type II. Profound congenital deafness, RP, and absent vestibular responses was defined as Usher I, while those exhibiting a congenital moderate to severe hearing loss, $\mathrm{RP}$, and no associated vestibular problems was defined as Usher II. ${ }^{2}{ }^{3}$ Although the existence of a type of US with progressive hearing loss had been proposed, ${ }^{45}$ there was no firm genetic evidence for a separate Usher III phenotype until a group of Finnish families with a phenotype of progressive hearing loss and RP were observed with linkage to a genetic marker on $3 \mathrm{q}^{6}{ }^{6}$ There is extensive genetic heterogeneity of Usher syndrome. Usher II was originally found to be linked to markers on chromosome $1 .^{78}$ The exclusion of Usher I families from the USH2a region locus showed that Usher I and II were non-allelic. ${ }^{79}$ The discovery of three Usher I genes followed: a group of French families with Usher I exhibited linkage to $14 \mathrm{q}$ whose locus is now called USH $1 \mathrm{a},{ }^{10}$ the most common form of Usher I (USH1b) was shown to be linked to $11 \mathrm{q},{ }^{11}$ and a set of Acadian families with Usher I (USH1c) displayed linkage to $11 \mathrm{p} .{ }^{12}$ The specific mutation responsible for USH1b has recently been shown to be in myosin VIIa. ${ }^{13}$ The remaining Usher genes have not been identified, but the location of USH2a has been narrowed down to a region of about $400 \mathrm{~kb}^{14}$

Heterogeneity was shown for Usher II by the identification of a family with a phenotype typical of Usher II not linked to USH2a, indicating the existence of at least one other Usher II gene. ${ }^{15}$ The proportion of non-USH2a linked families has been estimated at $12.5 \% .^{16}$ As noted above, Usher III has shown linkage to $3 \mathrm{q},{ }^{6}$ bringing the number of genetic loci involved in various subtypes of US to at least six.

Subtle phenotypic variations within the classic Usher II phenotype were observed within a group of 23 affected Dutch patients from 10 different families (all included in this study). Serial audiograms were available for 13 of the 23 patients, and subsequent analysis showed three of these 13 patients with a mild but definite progression of hearing $\operatorname{loss}^{17}$; however, these families showed linkage to USH2a. Given that these Usher II patients had progressive loss (presumably owing to allelic differences at the USH2a locus), it would be equally possible that some Usher III patients showing linkage to USH3 could show a stable congeni- 
tal hearing deficit. This would necessitate the use of both genotypic and audiological evaluations to make accurate diagnoses of Usher syndrome type and subsequent prognoses for affected patients.

Here we report the results of linkage analysis of 29 Usher II families collected from various regions throughout The Netherlands to determine (1) whether genetic heterogeneity of Usher II exists in the Dutch population and (2) if any observed genetic heterogeneity of Usher II can be explained as resulting from mutations at the USH3 locus. Given the probable existence of genetic heterogeneity of Usher II in the Dutch population, we then proceeded to evaluate the 1q41 linked families for linkage disequilibrium with regard to the different alleles at the linked loci. If present, disequilibrium could be a useful adjunct to estimate any specific family's likelihood of being one or the other Usher type.

\section{Methods}

SUBJECTS AND CLINICAL STUDIES

Families with clinical diagnoses of Usher II from different areas throughout the Netherlands were ascertained by referral from the Foundation of the Deaf-Blind, the Kalorama Institute for deaf-blind adults, and from the Nijmegen University Hospital Register. Twenty-nine families with 56 affected subjects were chosen as suitable for this study from a total of 36 Usher II families. Seven families proved too small or incomplete to provide sufficient linkage information. The results of previous audiological, vestibular, and visual tests and general medical reports of affected subjects and of first degree relatives with reported hearing or vision problems were available for confirmation of an Usher II diagnosis and at least one affected subject from each family was examined at the Nijmegen University Hospital.

A diagnosis of Usher II required (1) retinitis pigmentosa shown by retinal examination and by extent of night blindness and tunnel vision, (2) intact vestibular responses, (3) a "sloping" hearing loss, mild to moderate in the low frequencies and severe to profound in the higher frequencies, and (4) autosomal recessive inheritance pattern, to ensure accordance with accepted criteria. ${ }^{3}$ All affected family members underwent routine ophthalmic examination, including fundoscopic examinations and dark adaptation studies. Visual fields were evaluated by Goldmann perimetry. Electrophysiological retinal evaluations included an electro-oculogram (EOG) and electroretinography (ERG). The vestibular test battery included (1) an oculomotor screening battery to assess saccades, pursuit, and nystagmus, (2) alternate binaural bithermic caloric irrigations, and (3) rotational testing. Clinical audiometry was performed in various institutions over many years, but in all cases traditional measures of pure tone and speech discrimination thresholds were done using commercially available calibrated instrumentation according to established standards. Audiological examinations included speech discrimination, bilateral tympanograms, stapedial reflexes, and brainstem auditory evoked potentials (BAEP). Recent audiograms from patients examined at the University Hospital of Nijmegen were measured with an Interacoustic AC5 audiometer calibrated following the ISO 389 procedure according to the ISO 8253-1 standard. ${ }^{18}{ }^{19}$ The ISO 7029 method was used to establish individual P50 threshold values for presbyacusis. $^{20}$

\section{GENOTYPING}

Blood samples were collected and genomic DNA was extracted from lymphocytes using an Applied Biosystem 340A nucleic acid extraction machine. STRP genotyping was done according to standard protocols. Six chromosome 1q markers were chosen based on locus order as follows: cen - D1S419 - (0.2) D1S237 - (1.0) - D1S474 - (0.65) - AFM144 (0.65) - D1S490 - (0.5) - D1S229 - tel. Distances (in centimorgans) approximated from our total database of Usher II families are presented in parentheses between adjacent markers. The approximate location of USH2a is 1q41; DNA markers D1S474 and AFM144 are known to flank the USH2a gene. ${ }^{16}$ Chromosome $3 \mathrm{q}$ marker order and genetic distances were assumed as follows: cen D3S1555 - (1.0) - D3S1308(2.0) - D3S1299 (2.5) - D3S1279 - (2.0) - D3S1280 - tel. Marker D3S1299 shows no recombination with Usher III and D3S1308 and D3S1279 are the nearest established flanking markers. ${ }^{6}$

\section{ANALYSES}

Linkage analyses were performed with genotypic data from the 29 informative Dutch families. US was assumed to be an autosomal recessive disorder, fully penetrant in the affected homozygote, with a gene frequency of $1 / 140 .{ }^{1}$ No sporadic cases were assumed. The LINKAGE 5.03 program $^{21}$ was used to obtain two point and multipoint analyses. For the chromosome 1q analysis, D1S474 was arbitrarily chosen as the origin, and lod scores were calculated at approximately $0.4 \mathrm{cM}$ intervals for each family, with estimated interlocus distances given in the previous section. Only the two lod scores between the flanking markers and two outside each of each flanking marker were used in the analysis. The families' lod scores were analysed for heterogeneity using the A test computed with the HOMOG program. ${ }^{22}$ The model for chromosome $3 \mathrm{q}$ placed the origin at D3S1308 and lod scores were calculated in a similar manner using lods calculated at $0.5 \mathrm{cM}$ distances.

Linkage disequilibrium for the flanking markers D1S474 and AFM144 was examined in the 26 Usher IIa families by determining the frequency of specific alleles in phase with parental chromosomes carrying USH2a, compared against allele frequencies in phase with normal parental chromosomes. Only the 26 Usher IIa families were considered for this analysis; the three families which showed no linkage to 1q41 markers were excluded. Each allele was tested separately by using the standard chi-square test and Fisher's exact test. Since none displayed significant increase in 
Table 1 Multipoint lod scores for 29 Dutch Usher II families with markers flanking $3 q$ (USH3) and 1q41 (USH2a). 1372,1389 , and 1417 show consistently negative lods with USH2a; 1417 displays equally negative lods with USH3

\begin{tabular}{|c|c|c|c|c|c|c|c|c|}
\hline \multirow[b]{3}{*}{ Family } & \multicolumn{5}{|c|}{ Chromosome 3} & \multicolumn{3}{|c|}{ Chromosome 1} \\
\hline & \multicolumn{2}{|c|}{ D3S1308 } & \multicolumn{2}{|c|}{ D3S1299 } & \multirow{2}{*}{$\frac{D 3 S 1279}{4.5}$} & \multirow{2}{*}{$\frac{D 1 S 474}{0.0}$} & \multirow{2}{*}{$\begin{array}{l}A F M 144 \\
0.65\end{array}$} & \multirow{2}{*}{$\frac{D 1 S 490}{1.3}$} \\
\hline & 0.0 & 1.0 & 2.0 & 3.25 & & & & \\
\hline 956 & -0.99 & -1.29 & - & -2.48 & - & 0.58 & 0.58 & 0.58 \\
\hline 957 & -0.70 & -0.99 & - & -2.77 & - & 0.73 & 0.72 & 0.72 \\
\hline 1002 & $=$ & -2.01 & -1.82 & -1.92 & - & 1.48 & 1.48 & 1.48 \\
\hline 1003 & - & -2.20 & -1.60 & -1.23 & -0.98 & 1.83 & 1.82 & 1.83 \\
\hline 1004 & -0.83 & -1.13 & - & -2.62 & - & 0.55 & 0.55 & 0.55 \\
\hline 1005 & -0.66 & -0.96 & - & -2.30 & - & 0.84 & 0.84 & 0.84 \\
\hline 1006 & -5.15 & -4.87 & - & -6.48 & - & 1.76 & 1.76 & 1.76 \\
\hline 1007 & -1.40 & -1.83 & - & -4.14 & - & 1.57 & 1.57 & 1.58 \\
\hline 1008 & 0.71 & 0.42 & - & 0.11 & - & 0.72 & 0.72 & 0.71 \\
\hline 1009 & -1.10 & -1.21 & -1.36 & -1.67 & - & 1.95 & 1.95 & 1.95 \\
\hline 1010 & -1.15 & -1.46 & - & -1.37 & -1.06 & 0.84 & 0.84 & 0.84 \\
\hline 1011 & -0.81 & -1.11 & - & -2.61 & - & 0.30 & 0.30 & 0.30 \\
\hline 1366 & 0.14 & 0.16 & 0.17 & 0.21 & 0.25 & -0.05 & 0.12 & 0.25 \\
\hline 1368 & 0.12 & 0.12 & 0.13 & 0.13 & 0.13 & 0.12 & 0.12 & 0.12 \\
\hline 1369 & 0.25 & 0.27 & 0.28 & 0.33 & 0.38 & 0.07 & 0.07 & 0.07 \\
\hline 1370 & -0.25 & -0.27 & -0.28 & -0.28 & -0.28 & 0.61 & 0.61 & 0.62 \\
\hline 1371 & 0.13 & 0.12 & 0.13 & 0.13 & 0.13 & 0.12 & 0.12 & 0.12 \\
\hline 1372 & 0.11 & 0.11 & 0.11 & 0.12 & 0.13 & -1.47 & -1.77 & - \\
\hline 1373 & 0.13 & 0.12 & 0.12 & 0.12 & 0.13 & 0.12 & 0.12 & 0.12 \\
\hline 1376 & -0.63 & -0.80 & -1.12 & -0.73 & -0.52 & 0.11 & 0.12 & 0.12 \\
\hline 1386 & -2.21 & -2.81 & - & -5.80 & - & 0.58 & 0.59 & 0.60 \\
\hline 1387 & 0.09 & 0.10 & 0.10 & 0.12 & 0.13 & 0.12 & 0.12 & 0.12 \\
\hline 1388 & -0.53 & -0.84 & -1.67 & -1.16 & -1.22 & 0.43 & 0.44 & 0.44 \\
\hline 1389 & 0.25 & 0.25 & 0.25 & 0.25 & 0.25 & -1.25 & -1.47 & -1.94 \\
\hline 1391 & -2.3 & -1.79 & - & -1.25 & - & 0.50 & 0.50 & 0.50 \\
\hline 1404 & -1.16 & -1.51 & - & -3.16 & - & 1.29 & 1.29 & 1.28 \\
\hline 1405 & 0.25 & 0.25 & 0.25 & 0.25 & 0.25 & 0.25 & 0.25 & 0.25 \\
\hline 1415 & 0.48 & 0.49 & 0.50 & 0.50 & 0.50 & 0.07 & 0.07 & 0.07 \\
\hline 1417 & - & -4.34 & -4.00 & -4.20 & - & -5.35 & -5.80 & - \\
\hline \multirow[t]{3}{*}{ Totals } & - & -28.960 & - & -43.868 & - & 9.72 & 8.63 & - \\
\hline & & & & \multirow{2}{*}{\multicolumn{2}{|c|}{26 USH2a linked families $=$}} & 17.79 & 17.67 & 17.70 \\
\hline & & & & & & -8.07 & -9.04 & - \\
\hline
\end{tabular}

frequency with USH2a, correction for multiple testing was not necessary.

\section{Results}

The multipoint lod scores from both $1 \mathrm{q} 41$ and $3 q$ markers for each of the 29 families are summarised in table 1 . Lod scores for 1q41 in 26 of 29 Dutch families were consistent with linkage to USH2a. The multipoint maximum lod for these 26 families was 17.79, and occurred between D1S474 and AFM144. Three of the 29 families excluded linkage to USH2a (1372, 1389 , and 1417) with a combined lod of -8.07 . Seven less informative families $(1366,1368$, $1369,1371,1387,1405$, and 1415) could not be completely excluded from linkage from either locus. Composite 3q lod scores from all

Table $2 A$ tests for heterogeneity were done with $1 q 41$ and $3 q$ lods from all 29 Dutch Usher families (table 1). Significant linkage heterogeneity was observed with USH2a (H2 v H1), but not with USH $3, \chi^{2}(1)=0.0$ (data not shown)

\begin{tabular}{llll}
\hline Hypothesis & $d f$ & $\chi^{2}$ & L ratio \\
\hline H2 $v$ H1 & 1 & 22.13 & $6.39 \times 10^{4}$ \\
H1 $v$ H0 & 1 & 43.55 & $2.86 \times 10^{9}$ \\
H2 $v$ H0 & 2 & 65.68 & $1.83 \times 10^{14}$ \\
\hline
\end{tabular}

$\mathrm{H} 2$ = linkage with heterogeneity.

$\mathrm{H} 1=$ linkage with homogeneity.

$\mathrm{HO}=$ no linkage.
29 families summed together are extremely negative, with the highest at -28.96 between D3S1308 and D3S1299.

Lod scores for the 1q41 location were analysed by the A test for heterogeneity and the results are summarised in table 2 . The test for heterogeneity with linkage versus homogeneity with linkage gave a $\chi^{2}(1)=22.13(\mathrm{p}<0.001)$ establishing that both 1q41 linked and unlinked families were present in the sample. The proportion of unlinked families $(1-\alpha)$ was estimated at 0.104 . Conditional probabilities of three unlinked families $(1372,1389$, and 1417) were calculated to be $0.00,0.06$, and 0.00 respectively, indicating that these were likely not to be Usher IIa families. Conditional probabilities of the other presumably linked families ranged between $0.88-0.99$. The A test for heterogeneity was also done on the set of $3 \mathrm{q}$ lod scores and the results were not significant $\left(\chi^{2}(1)=0.0\right)$, which suggests USH3 is not responsible for the heterogeneity present in this Dutch sample.

Haplotypes of $1 \mathrm{q} 41$ and $3 \mathrm{q}$ markers were compiled for all 29 Dutch Usher II families. Twenty-six of these 29 showed haplotypes compatible with linkage to the USH2a locus, with no apparent double crossovers in the $1 \mathrm{q} 41$ region, whereas haplotypes for $3 \mathrm{q}$ markers

Table 3 Distribution of alleles in parental Usher and normal chromosomes for 1941 flanking loci. Numbers: Usher chromosomes/normal chromosomes. No linkage disequilibrium is evident for any allele with USH2a at either locus

\begin{tabular}{|c|c|c|c|c|c|c|c|c|c|c|c|}
\hline \multirow[b]{2}{*}{ Flanking loci } & \multicolumn{10}{|c|}{ Alleles } & \multirow[b]{2}{*}{$\Sigma$} \\
\hline & 1 & 2 & 3 & 4 & 5 & 6 & 7 & 8 & 9 & 10 & \\
\hline $\begin{array}{l}\text { D1S474 } \\
\text { AFM144 }\end{array}$ & $8 / 6$ & $26 / 35$ & $15 / 24$ & $0 / 0$ & $1 / 0$ & & & & & & $50 / 65$ \\
\hline AFM144 & $0 / 0$ & $0 / 0$ & $0 / 0$ & $1 / 4$ & $32 / 31$ & $0 / 0$ & $0 / 2$ & $0 / 0$ & $0 / 2$ & $18 / 24$ & $57 / 63$ \\
\hline
\end{tabular}


Family pedigrees

Non-linkage to USH2a

Family 1372
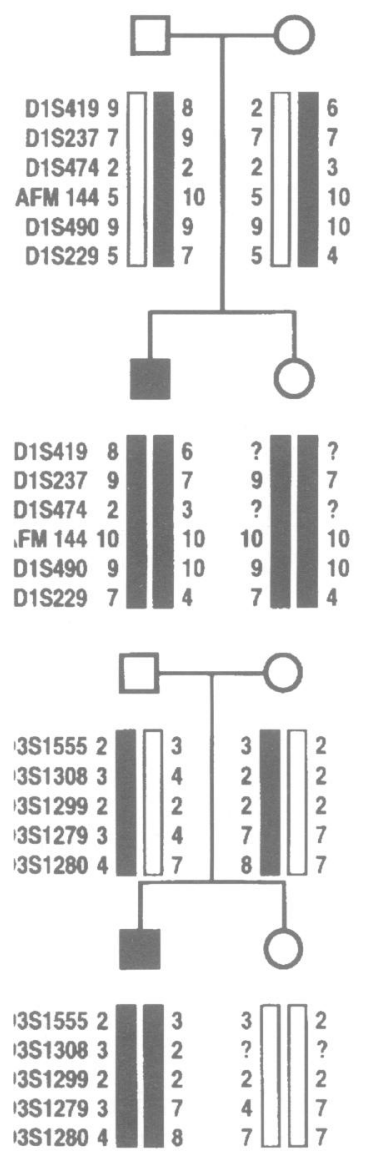

Family 1389
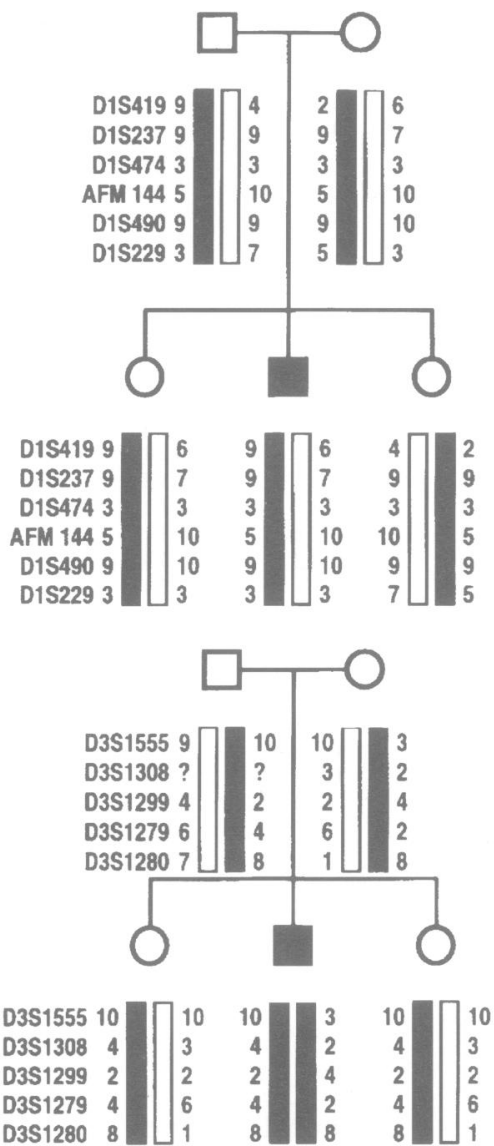

Family 1417
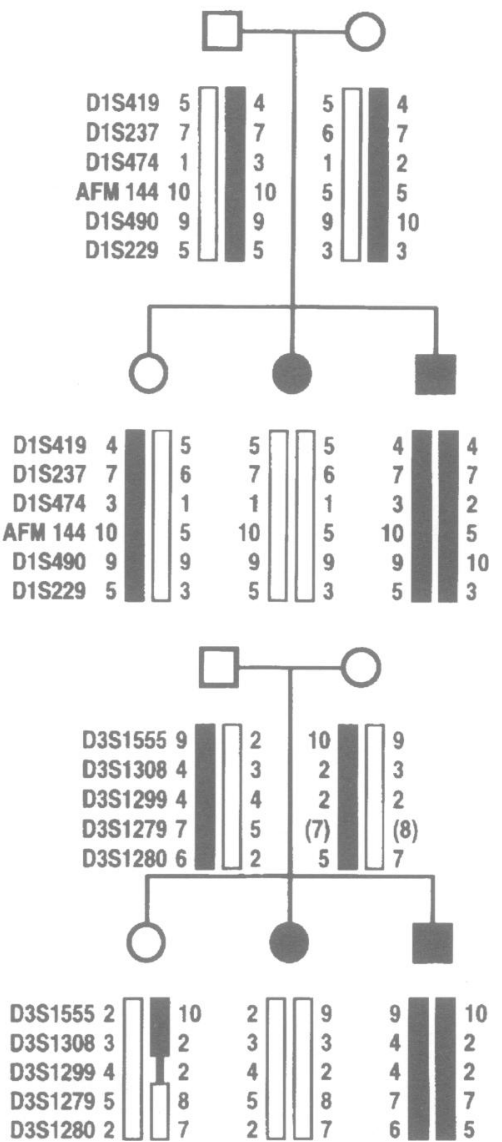

Figure 1 Abbreviated pedigrees of three Dutch Usher II families with 1941 and $3 q$ haplotypes of each subject underneath. Chromosomes are illustrated as black/white bars. Putative crossover areas are represented by lines. Parental phases shown are the most likely based upon minimum number of crossovers. Inferred types are in parentheses () and unknown types are shown as question marks. Row 1: the USH2a region shows no linkage with affected status in any of these three families. Row 2: given phase as illustrated, family 1417 can be excluded as linked to USH3, but 1372 and 1389 cannot be excluded without further genotyping of additional markers/subjects.

exhibited no consistent linkage with an Usher II phenotype. Fig 1 depicts pedigrees and haplotypes of the three Dutch Usher II families unlinked to 1q41. Families 1389 and 1372 cannot be excluded as Usher type III, although family 1417 shows no cosegregation with $\mathrm{USH} 2 \mathrm{a}$ and is therefore categorised as Usher IIb.

Table 3 shows the distribution of allele frequencies for two 1q41 markers that closely flank USH2a. None of the alleles displayed significant differences between gene frequencies of the parental Usher IIa chromosomes versus the normal parental chromosomes, indicating that linkage disequilibrium is not present in this Dutch sample.

\section{Discussion}

Three Dutch families have shown no linkage to USH2a and are therefore considered candidates for Usher IIb; one family has been identified as Usher IIb since it shows no linkage to USH3 either. Our results show no convincing evidence for Usher type III in this Dutch sample, although the two ambiguous families may prove to be linked to USH3 after further genotyping with more informative markers. Ten percent of this Dutch population with Usher II fail to show linkage to the USH2a locus, indicating that the unlinked type of Usher II occurs at approximately the same frequency in the Dutch population as previously observed. ${ }^{16}$

Given the observation of audiological variation within the classical Usher II phenotype, ${ }^{17}$ our results imply that one or more different allelic mutations at the USH2a locus are responsible for this variation. Alternatively, a progressive hearing loss rather than stable hearing loss could be the result of other elements, such as effects of various genotypic backgrounds or interactions between the environment and the USH2a gene. However, this hypothesis cannot be tested until USH2a and USH3 are identified and sequenced.

Subjects affected with Usher IIb cannot be phenotypically distinguished from those with Usher IIa. ${ }^{6{ }^{15-17}}$ At present, linkage analysis in conjunction with reliable clinical data such as serial audiograms and stringent clinical protocol remains the most effective and reliable 
method of identifying non-USH2a families from families with Usher IIa or Usher III. As more Usher IIb families are ascertained, a genome search for additional loci will become feasible.

The research was supported by NIH-NIDCD PO DC01813-01 and grant 89-198 from the RP/Fighting Blindnes Foundation of the USA. The Dutch study was supported by grants from Stichting De Drie Lichten, Stichting Het Heinsius Houbold Fonds, Landelijke Stichting voor Blinden en Slechtzienden, Nederland se Stichting voor het Gehandicapte Kind, and the Algemene Nederlandse Vereniging ter Voorkoming van Blindheid. We wish to thank D Hoover and P Kimberling for their technical expertise. We are also indebted to the Dutch Foundation for the Deaf and Blind, the Dutch Association of Usher patients, and all the patients and relatives for their participation in this study.

1 Hallgren B. Retinitis pigmentosa combined with congenita deafness; with vestibulo-cerebellar ataxia and neural abnormality in a proportion of cases. Acta Psychiatr Scand abnormality in a proporti

2 Kimberling WJ, Moller C. Clinical and molecular genetics of Usher syndrome. $7 \mathrm{Am}$ Acad Audiol 1995;6:63-72.

3 Smith RJH, Berlin CJ, Hejmancik JF, et al. Clinical diagnosis of the Usher syndromes. Am $\mathcal{F}$ Med Genet 1995;
50:32-8.

4 Merin S, Abraham FA, Auerbach E. Usher's and Hallgren's syndrome. Acta Genet Med Gemellol (Roma) 1974;23:49 55.

5 Karjalainen S, Pakarinen L, Terasvirta M, Kaariainen $\mathrm{H}$. Vartiainen E. Progressive hearing loss in Usher's syndrome. Ann Otol Rhinol Laryngol 1989;98:863-6.

6 Sankila EM, Pakarinen L, Kaariainen H, et al. Assignment of an Usher syndrome type III (USH3) gene to of an Uner syndrom type 1995; 19:93-8.

7 Kimberling WJ, Weston MD, Moller C, et al. Localization of Usher syndrome type II to chromosome 1q. Genomics Usher syndrom

8 Lewis RA, Otterud B, Stauffer D, Lalouel JM, Leppert M. Mapping recessive ophthalmic diseases: linkage of the locus for Usher syndrome type II to a DNA marker on chromosome 1q. Genomics 1990;7:250-6.

9 Kaplan J, Guasconi G, Bonneau D, et al. Usher syndrome type I is not linked to DIS81 (pTHH 33): evidence for genetic heterogeneity. Ann Genet (Paris) 1990;33:105-8.

10 Kaplan J, Gerber S, Bonneau D, et al. A gene for Usher syndrome type I (USH1A) maps to chromosome $14 \mathrm{q}$. Genomics 1992;14:979-87.

11 Kimberling WJ, Moller CG, Davenport S, et al. Linkage of Usher syndrome type I gene (USH1B) to the long arm of chromosome 11. Genomics 1992;14:988-94.

12 Smith RJH, Lee EC, Kimberling WJ, et al. Localization of two genes for Usher syndrome type I to chromosome 11. Genomics 1992;14:995-1002.

13 Weil D, Blanchard S, Kaplan J, et al. Defective myosin VIIA gene responsible for Usher syndrome type $1 \mathrm{~B}$. Nature 1995;374:60-1.

14 Sumegi J, Wang JY, Zhen DK, et al. The construction of a yeast artificial chromosome (YAC) contig in the vicinity of the Usher syndrome type IIa (USH2a) gene in 1 q41. Genomics (in press).

15 Pieke-Dahl S, Kimberling WJ, Gorin MB, et al. Genetic heterogeneity of Usher syndrome type II. $\mathcal{F}$ Med Genet 1993; 30:843-8.

16 Kimberling WJ, Weston MD, Moller C, et al. Gene mapping of Usher syndrome type IIa: localisation of the gene to a 2.1-cM segment on chromosome 1q41. Am f Hum Genet 1995;56:216-23.

17 van Aarem A, Huygen PLM, Pinckers AJLG, et al. Stable and progressive hearing loss in type $2 \mathrm{~A}$ Usher syndrome. Ann Otol Rhinol Laryngol (in press).

18 ISO 8253-1. Acoustics - Audiometric test methods. Part I. Basic pure tone air and bone conduction threshold audiometry, 1985.

19 ISO 389. Acoustics - Standard reference zero for the calibration of pure tone air conduction audiometers, 1985.

20 ISO 7029. Acoustics - Thresholds of hearing by air conduction as a function of age and sex for otologically normal persons, 1984.

21 Lathrop GM, Lalouel JM, Julier C, Ott J. Multilocus linkage analysis in humans: detection of linkage and estimation of recombination. Am 7 Hum Genet 1985;37:482-98.

22 Ott J. Analysis of human genetic linkage. Baltimore: Johns Hopkins Univerity Press, 1991. 